\title{
IN VITRO DETERMINATION OF EFFICACY OF EXTRACTS OF SELECTED MEDICINAL PLANTS AGAINST Alternaria alternata ISOLATED FROM LEAF SPOT OF BAEL (Aegle marmelos) \\ PRIYA KUMARI ${ }^{1}$
}

Department of Botany, B.R. Ambedkar Bihar University, Muzaffarpur, Bihar, India

\begin{abstract}
Alternaria alternata was isolated from leaf spots of Bael (Aegle marmelos). The fungus was maintained as pure culture in the laboratory. Experiments were done to determine the efficacy of antifungal activity of extracts of selected medicinal plants in vitro. Chirchiri, (Achyranthes aspera), Garlic (Allium sativa), Datura (Datura metal), Lippia nodiflora, Neem (Azadirachta indica) and Tulsi (Ocimum sanctum) were used for the extraction from leaves and cloves etc. Three different concentrations 5,10 and $15 \%$ were used in the culture. The fungitoxic capability was determined by measuring the radial growth among the treated cultures as well as in the control. In the present study, it was observed that extract of clove of garlic at its all the three concentrations viz., 5 , 10 and $15 \%$ could inhibit the radial growth of the fungus which was $78.95,85.05$, and $88.54 \%$ respectively that was the maximum. This was followed by the extract of neem leaves that was $\mathbf{7 5 . 7 7 , 8 2 . 3 5}$ and $\mathbf{8 7 . 1 2 \%}$ respectively. It was further observed that leaf extract of Chirchiri had the minimum inhibitory activity at all the concentrations used, that was $63.73,68.14$ and $72.52 \%$ only. It was further observed that leaf extract of Ocimum sanctum inhibited the radial growth at all its three concentrations which was next to neem leaf extract that was $75.32,81.07$, and $85.48 \%$ respectively. This was followed by leaf extract of $\mathrm{Lippia}$ that was $74.53, \mathbf{8 0 . 6 2}$ and 84.46 respectively. Therefore, leaf and clove extracts of different medicinal plants revealed, antifungal activities at different concentrations with different quantum of action.
\end{abstract}

KEYWORDS: Medicinal Plants, Antifungal, Radial Growth, Efficacy, Quantum, Alternaria alternata, Bael (Aegle marmelos)

Aegle marmelos is an important medicinal plant of family Rutaceae. The tree is thorny, much branched and deciduous. In addition its leaves are used for the worship of Lord Shiva. Both unripe and ripe fruits are used for the treatment of different diseases. Unripe fruit is roasted and the shell is removed. The seeds from the pulp are also removed. The roasted pulp is taken to cure all types of digestive problems. Ripe fruits are used similarly. The shell and seeds are removed while the pulp is taken for the treatment of dysentery, piles, peptic ulcer. It is also used to cure the hair loss, hepatitis, to glow the skin. Even flowers are roasted in ghee and used to cure diarrhea. Its regular use may help to cure tuberculosis. It is also beneficial in case of different gynecological problems. Similarly, it cures urinary diseases. Its regular use helps to control blood sugar. Juice of leaves with honey is given to cure fever. Similarly, roasted flowers in ghee help in epilepsy. It is best treatment for piles. Here extract of unripe fruit is given to the person suffering from piles.

However, different pathogen causes disease to this medicinally important plant among which the fruit rot and leaf blight both caused by fungal pathogens are common. These diseases are controlled by spraying fungicides, but there are reports that fungal pathogens are being controlled by the use of extracts taken from roots, leaves, bark etc. of the commonly used medicinal plants. We get several references related with this. Some of them may be mentioned here such as; Rana et al., 1999; Sindham et al., 1999; Lal and Upadhyay, 2002; Samuel et al., 2000; Abdul et al., 2001; Singh and Mazumdar, 2001; Sriniwasan et al., 2001; Prabha et al., 2002; Chaudhary et al., 2003; Sharma and Tripathi, 2006; Mathivana and Pravathy, 2007; Saha et al., 2008; Raja and Reddy, 2008; Elumalai et al., 2009; Mishra et al., 2009; Saba et al., 2010; Raja, 2010; Balai and Ahir, 2011; Gahukar, 2012; Pareek et al., 2012; Kantwa et al., 2014; Manilal and Idhayadhulla, 2014; Showkat et al., 2015; Maria et al., 2018; Rani et al., 2018.

During survey of medicinal plants in selected areas of Hajipur subdivision, it was noted that the leaves of Bael are infected by plant pathogenic fungi, Alternaria alternata. It causes early defoliation, if the infection is severe. In this case farmers suffer a considerable economic loss, because due to early defoliation, immature fruits also drop. The aim of this work was to evaluate in vitro the potential antifungal activity of selected medicinal plant extracts at different

${ }^{1}$ Corresponding author 
concentrations, against Alternaria alternata which was isolated from the infected leaf of Bael.

\section{MATERIALS AND METHODS}

In the present study, six different plants which are commonly used as medicinal plants were selected. They were Achyranthes aspera, Allium sativa, Datura metal, Lippia nodiflora, Azadirachta indica, and Ocimum sanctum. Allium cepa, bulbs were purchased where as the leaves of rest plants were collected from their natural population. All the plant materials were washed properly in the running tap water and then rinsed with sterilized distilled water. Leaves were dried properly to remove the surface water. 100 grams of leaves from each plant and 100 $\mathrm{g}$ of cloves of garlic was taken separately. These leaves were chopped and crushed in a pre-sterilized mortar with the help of pestle by adding $100 \mathrm{ml}$ sterile water. The extract was filtered through two layered muslin cloth in a clean beaker. These extracts were centrifuged at $4000 \mathrm{rpm}$ to remove any extra residues. They were stored in a bottle with proper stopper and used as stock solution. To determine the antifungal activity of these extracts method used by Singh \& Majumdar (2001) with slight modification was used. Five, ten and fifteen $\mathrm{ml}$ of stock solution of the above plants was mixed with 95, 90 and $85 \mathrm{ml}$ of presterilized molted Potato, Dextrose Agar Medium, respectively. Thus for each extract the concentration became 5, 10 and 15 percent. Manually the culture flasks were shaken to make the solution, homogeneous. Presterilized Petri plates were taken. $20 \mathrm{ml}$ of above medium was poured into it. Medium without extract was used as control. Three replications were maintained for each treatment.

Pure culture of Alternaria alternata was used for inoculation. 8 days old cultures was used for the inoculum. The pre-sterilized cork borer was used for cutting a disc of $5 \mathrm{~mm}$ mycelial mat from the periphery of the culture. All the experiments were done in the sterilized area of Laminar Flow Air Chamber. The disc was placed in the middle of the culture plate and it was placed upside down so that the mycelial mat was in direct contact with the culture medium. Inoculation was also done in culture plate having no extract.

The inoculated Petri plates were incubated in the culture room at $26 \pm 1^{\circ} \mathrm{C}$. These cultures were observed on an alternate day and cultures showing any contamination was replaced and disposed after autoclaving. The colony diameter was measured on 8 days of incubation. Percent inhibition of the extract at different concentration was calculated by applying the formula as proposed by Vincet (1947).

$\%$ growth inhibition $=\frac{C-T}{C} \times 100$

Where,

$\mathrm{C}=$ diameter of the colony in the control.

$\mathrm{T}=$ diameter of the colony in the treated cultures.

Inoculation for each concentration was done in 15 plates and mean of the data obtained, was tabulated for discussion. Here they are represented by the graphs.

\section{RESULTS AND DISCUSSION}

Fungitoxic efficacy of six medicinal plant's extract was tested at different concentrations as mentioned in the Materials and Methods, against radial mycelial growth of the phytopathogenic fungus Alternaria alternata, isolated form leaf spot of Aegle marmelos. Perusal of the data represented by the graph clearly revealed that extracts taken from six different medicinal plants at different concentrations inhibited the mycelial growth with different intensity. Here extract of cloves of garlic at its all three concentrations viz., 5, 10 and 15\% inhibited the radial mycelial growth which was the maximum that was 78.95, 85.05 and 88.21 per cent respectively. At the similar concentration extract of Neem leaves inhibited the radial growth which was $75.77,82.35$ and $87.12 \%$ respectively. This was followed by the leaf extract of Ocimum sanctum, Tulsi that was, 75.32, 81.07 and 85.46 respectively. It may be further noted that leaf extract of Achyranthes aspera at its all three different concentrations inhibited the radial growth of the mycelium of Alternaria alternata which was 63.73, 68.14 and 72.52 per cent respectively. However, this was the lowest in comparison to the extracts of other medicinal plants at the aforesaid concentrations. It may be noted that at the similar concentrations, the radial growth of the mycelium of $A$. alternata was inhibited more by the leaf extract of Datura metal in comparison to Lippia nodiflora.

Generally, fungal pathogens are controlled by the used of different chemical fungicides. These fungicides are being held responsible for water and soil pollution. Now a day there are attempting to develop ecofriendly control methods for the fungal pathogens. Use of extracts taken 
from different parts of plant is getting more popularity. Saha et al; (2008) reported that extract of Allium sativum, Datura metal and Zingiber officinale could inhibit $100 \%$ spore germination and mycelial growth of Pestalotiopsis thea, Curvularia eragrostidis and Colletotrichum camelliae.

Saba et al., (2010) reported that extracts of selected medicinal plants such as Majorana syriaca, Rosmarinus officinalis, Salvia fruticosa, Hibiscus sabdariffa and Santolina chamaecyparisus suppressed mycelial growth in vitro. At $25 \%$ of concentrations the inhibition was up to $90 \%$.

Pareek et al., (2012) also reported that extract of selected medicinal plants could inhibit mycelial growth and sporulation in Alternaria alternata and the percentage of inhibition was equivalent to chemical fungicides. All these findings support the findings of present work as here also mycelial growth was reduced at different concentrations of extracts of selected medicinal plants. Kantwa et al., (2014); Maria et al., (2015); Showkat et al., (2015); Jayapradha and Raja (2016); Nidhika Rani et al., (2018) all have reported that extract taken from different medicinal plants have fungicidal activity. Therefore, findings of the present work corroborate with the above findings as here also extracts of six medicinal plants could reduce the radial growth of Alternaria alternata, in vitro. Here there is need of extensive research for the selection of best medicinal plant and suitable concentration to be used as fungicides. This would be beneficial for organic farming as it would be ecofriendly method of control of the fungal pathogens.

Graph 1: Showing impact of different concentrations of extracts of selected medicinal plants on mycelial growth of Alternaria alternata

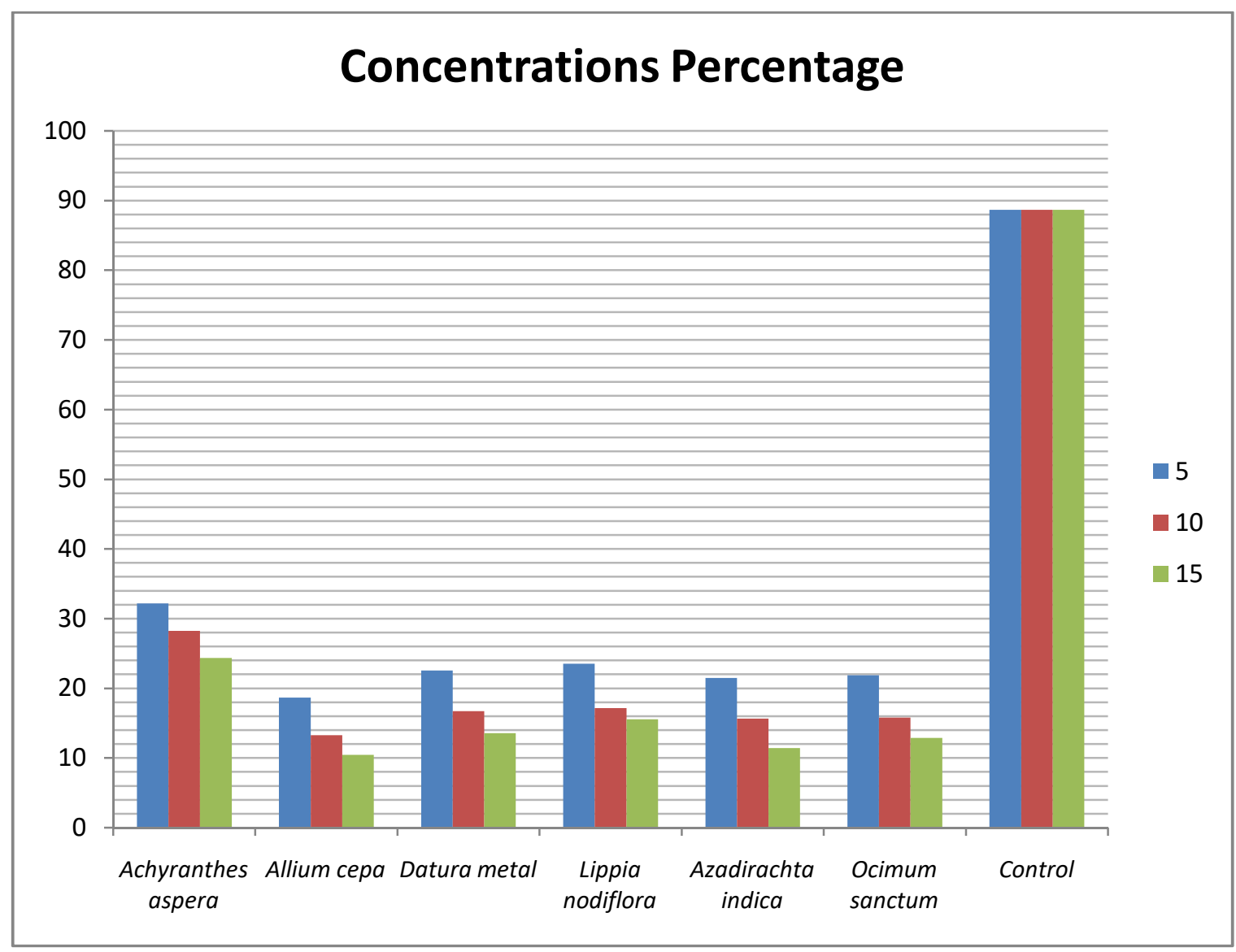

Radial growth of $A$. alternata in ( $\mathrm{mm})$ in the treated and controlled cultures 
Graph 2: Showing impact of different concentrations of extracts of selected medicinal plants on mycelial growth of Alternaria alternata

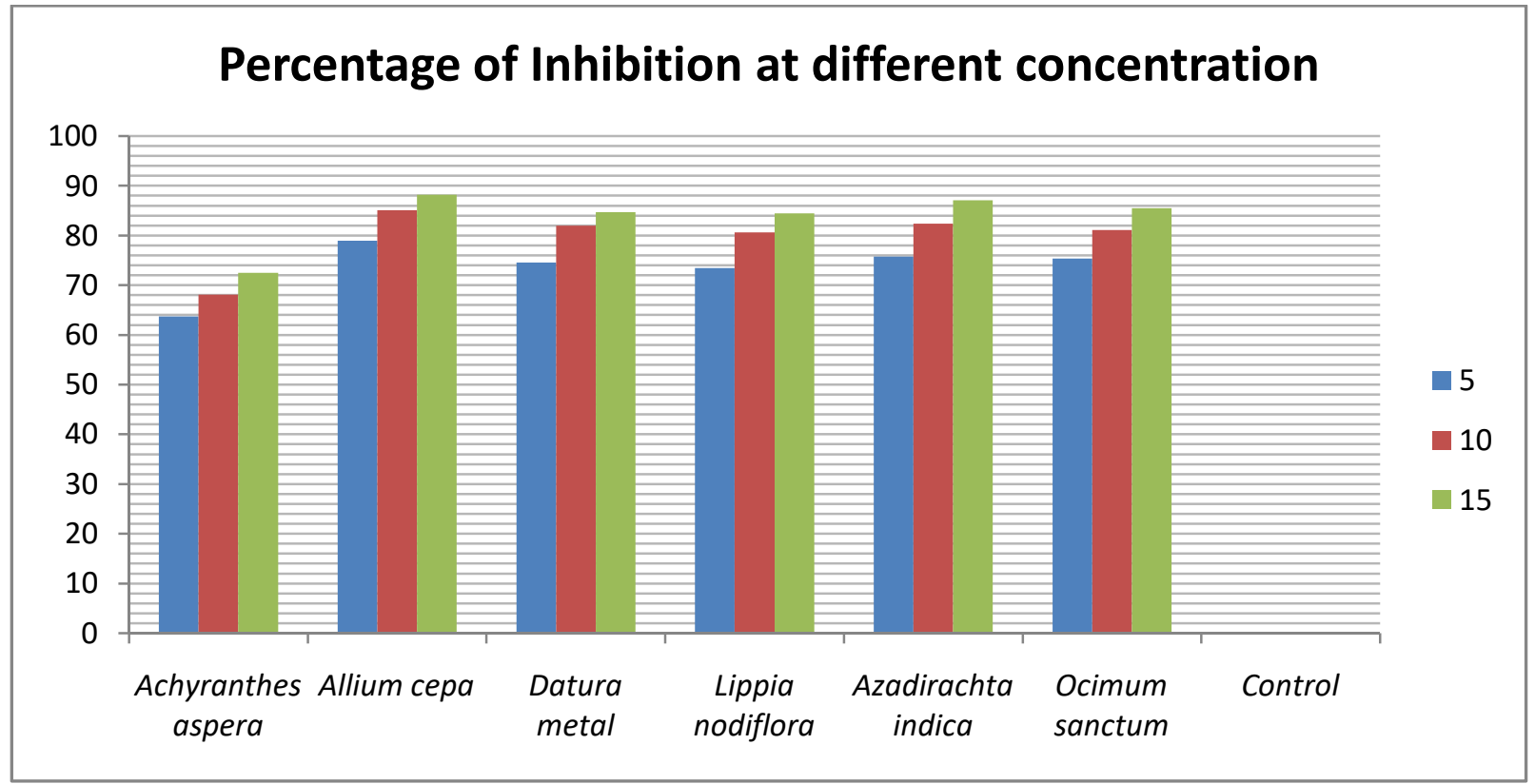

Radial growth in (mm). \% of Inhibition. Percentage inhibition of radial growth of mycelium of $A$. alternata in the treated cultures

\section{ACKNOWLEDGEMENT}

Author is grateful to the Head, Department of Botany, B.R.A. Bihar University for providing laboratory and library facilities during the work.

\section{REFERENCES:}

Abdul H., Khan M.A. and Chohan R.A., 2001. In vitro evaluation of various antagonists and plant extracts against mycelial growth of Alternaria solani. P.J. of Phytopathology, 13(2): 127-129.

Balai L.P. and Ahir R.R., 2011. Evaluation of plant extracts and biocontrol agents against leaf spot of brinjal. Indian Phytopath., 64(4): 378-380.

Chaudhary R.F., Patel and Chaudhari S.M., 2003. In vitro evaluation of different plant extracts against Alternaria alternata causing early blight of Potato. Journal of Indian Potato Association, 30: 141-142.

Elumalai E.K., Chandra Shekharan N., Thirumalai T., Shivakumar C., Vivian Theresa S. and David E. 2009. Achyranthes aspera leaf extract inhibited fungal growth. Int. J. of Pharm. Tech. Research, 1(4): 1576-1579.

Gahukar R.T., 2012. Evaluation of plant derived products against pests and diseases of medicinal plants: a review. Crop. Prot., 6(6): 938-949.

Jayapradha C. and Raja I.Y., 2016. A review of ecofriendly management of Alternaria species. Indian Journal of Hill Farming, 29(2): 106-119.

Kantwa S.L., Tetarwal J.P. and Shekhawat K.S., 2014. In vitro effect of fungicides and phytoextracts against Alternaria alternata causing leaf blight of ground nut. J. of Agric. and Veterinary Science, 7(6): 2831.

Lal H.C. and Upadhyay J.P., 2000. Biological control of leaf blight caused by Alternaria tenuissima in pigeon pea. Journal Biocontrol, 16(2): 141-144.

Manilal A. and Idhayadhulla A., 2014. Potential in vitro antimicrobial efficacy of Holigarna annottiana. Assian Pac. J. Trop. Biomed., 4(1): 25-29. 
Maria D.C.S., Costa H.B., Patricia M.B.F., Jose A.V. and Meira D.D., 2016. Antifungal activity of plant extracts with potential to control plant pathogens in pineapple. Asian Pacific Journal of Tropical Biomedicine, 6(1): 26-31.

Mathivanan and Prabavathy, 2007. Effect of Carbindazim and Mancozeb on Alternaria leaf blight and seed yield in Sun flower. (Helianthus annus L.) Arch. Phytopath. Plant Protect, 40(7): 90-96.

Mishra A.K, Mishra A., Kehri H.K., Sharma B. and Pandey A.K., 2009. Inhibitory activity of Indian spice plant, Cinamomum zeylamica extract against Alternaria solani and Curvularia lunata, the pathogenic demateous moulds. Inn. Clin. Microbial Antimicrob., 8: 9-14.

Pareek D., Khokhar M.K. and Ahir R.R., 2012. Management of leaf spot pathogen Alternaria alternata of Cucumber (Cucumis sativus). Green Farming, 3(5): 569-573.

Prabha P., Bohra A. and Purohit P., 2002. Antifungal activity of various spices plants against phytopathogenic fungi. Cab. Abst., 15: 615-6177.

Raja P., 2010. Fungitoxic properties of plant extracts against Alternaria tenuissima infecting egg plant in India. Indian Phytopath, 63(1): 45-46.

Raja P. and Reddy R., 2008. Efficacy of fungicides on leaf spot of Egg plant caused by Alternaria tenuissima. Ann Pl. Protect Sci., 16(1):203-207.

Rana B.K., Taneja V. and Singh U.P., 1999. Antifungal activity of an aqueous extract of leaves of garlic creeper (Adenocilymma alliaceum). Pharm. Biol., 37: 13-16.

Rani N., Lal H.C., Kumar P., Ekka S. and Kumar N., 2018. In vitro evaluation of fungicides, Bioagents and plant extracts against Alternaria spp. infecting pigeon pea. Int. J. of Current. Microbiol App. Sci., 7: 5112-5118.

Saba J., Goussous, Fira M., Abu S. and Tahhan R.A., 2010. Antifungal activity of several medicinal plants extracts against the early blight pathogen (Alternaria solani). Archives of Phytopathology and Plant Protection, 43(20): 1745-1757.

Saha D., Dasgupta S. and Saha A., 2008. Antifungal activity of some plant extracts against fungal pathogens of tea, (Camellia sinensis). Pharmaceutical Biology, 43(1): 87-91.

Samuel J.K., Andrews B. and Jebashree H.S., 2000. In vitro evaluation of the antifungal activity of Allium sativum bulb extract against Trichophyton rubrum, a human skin pathogen. World J. Microbiol. Biotechnol., 16: 617-620.

Sharma N. and Tripathi A., 2006. Fungitoxicity of the essential oil of Citrus sinensis on post harvest pathogens. World J. MIcrobiol. Biotechnol., 22(6): 587-593.

Sharma R.A. and Singh R., 2013. A review of Phyla nodiflora L: A wild wet land medicinal herb. Int. J. Pharm. Sci. Rev. Res., 20(1): 57-63.

Showkat A.Z., Gazala R. and Prashar R., 2015. Studies on leaf spot disease of mango and its management. Int. J. of Pharma and Bio Sciences, 6(1): 769-776.

Sindhan G.S., Hooda I. and Prashar R.D., 1999. Effect of some plant extracts on the vegetative growth of root rot causing fungi. J. Mycol. Plant Pathol., 29: 110-111.

Singh J. and Majumdar V.L., 2001. Efficacy of plant extracts against Alternaria alternata, the incitant of fruit rot of pomegranate (Punica granatum L.) Journal of Mycology and Plant Pathology, 13: 346-349.

Sriniwasan D., Nathan S., Suresh T. and Perumalsamy P.L., 2001. Antimicrobial activity of certain Indian medicinal plants used in folkloric medicine. J. Ethonpharmacol., 74: 217-220.

Zamora C.M.P., Carola T.A. and Nanez M., 2018. Antimicrobial activity and chemical composition of essential oil from verbenaceae species, growing in South America. Molecules, 23: 544-565. 